\title{
ReSEARChArticle
}

\section{Chemical composition and antifungal activity of the crude extracts isolated from Zingiber officinale against Macrophomina phaseolina}

\author{
SUMATI CHOUDHARY, ANIL KUMAR DWIVEDI AND POOJA SINGH
}

\begin{abstract}
SUMMARY
Fungitoxic property of extracts of rhizome of Zingiber officinale against $M$. phaseolina were tested at different concentrations of 5 per cent, 10 per cent and 20 per cent under in vitro conditions using poisoned food techniques. Extracts of rhizome of Zingiber officinale showed antifungal activity against the pathogen and with an increase in the concentration of extracts, a progressive decrease in mycelial growth was observed. The essential active compound of plant material is the fraction isolated by means of several methods such as TLC, column chromatography and HPLC and is chemically defined as terpenoids namely monoterpene. The identification of active component was done by comparing the retention time $\left(\mathrm{R}_{t}\right)$ and chromatographic peaks of sample of Zingiber officinale rhizomes with their respective active component zingiberene and camphene. The HPLC fingerprint profile of the sample of Zingiber officinale rhizomes showed major peaks at the retention time of 5.32 and $2.83 \mathrm{~min}$, respectively, whereas, the pure standard of zingeberene and camphene showed major peaks at the retention time $5.35 \mathrm{~min}$ and $2.87 \mathrm{~min}$, respectively.
\end{abstract}

Key Words : Zingiber officinale, Antifungal, Macrophomina phaseolina, Zingeberene, Camphene

How to cite this article : Choudhary, Sumati, Dwivedi, Anil Kumar and Singh, Pooja (2017). Chemical composition and antifungal activity of the crude extracts isolated from Zingiber officinale against Macrophomina phaseolina. Internat. J. Plant Sci., 12 (2): 204-209, DOI: 10.15740/HAS/IJPS/12.2/204-209.

Article chronicle : Received : 13.05.2017; Revised : 22.05.2017; Accepted : 10.06.2017 